\title{
Reduction of seating pressure using FES in patients with spinal cord injury. A preliminary report.
}

\author{
A C B Ferguson Dip COT MCSP MSc, ${ }^{1} \mathrm{~J}$ F Keating FRCS, ${ }^{1}$ M A Delargy MRCP,${ }^{2}$ \\ B J Andrews BSc MSc PhD ${ }^{1}$ \\ ${ }^{1}$ Bioengineering Unit, University of Strathclyde, Glasgow; ${ }^{2}$ Philipshill Hospital, East \\ Kilbride Road, Glasgow, Scotland.
}

\begin{abstract}
The aim of this study was to investigate the use of functional electrical stimulation (FES) as a means of pressure sore prevention in seated spinal cord injured (SCI) subjects. Nine SCI subjects took part in tests in which electrical stimulation was applied to the quadriceps with the lower legs restrained. Ischial pressures were measured during periods of quiet sitting and FES application. A strain gauged lever arm was used to measure the knee moment during quadriceps stimulation. The average pressure drop at the right and left buttocks was $44 \mathrm{mmHg}$ and $27 \mathrm{mmHg}$ respectively. In general the greatest reductions occurred in subjects with larger knee moments; however, there was no direct relationship between the pressure reduction obtained and the quadriceps strength. This form of FES may be useful as a prophylactic aid in the management of pressure sores in SCI subjects.
\end{abstract}

Key words: pressure sores; sitting; functional electrical stimulation (FES).

\section{Introduction}

Pressure sores are a major cause of morbidity in patients with spinal cord injury, and a huge drain on financial resources in the units responsible for their management. The prevalence of pressure sores in patients with spinal cord injury has been estimated to be in excess of $20 \%$ in some studies. ${ }^{1}$ The ischial region is the commonest site of sore formation since it is also the region where the highest pressures are encountered. ${ }^{2.3 .4}$ Because of the difficulty and cost of treating established ischial pressure sores, prevention has played an important role in the rehabilitation of patients with spinal cord injury. Traditionally this has focused on the development of specialised seating surfaces and the performance of pressure relieving push-ups by the patients. However, patient compliance in performing regular ischial pressure relieving push-ups has been demonstrated to be variable.

The reduction of seating pressures using electrical stimulation has been suggested by Levine et al, ${ }^{6}$ who have reported pressure reductions by stimulating the gluteal muscles in seated able bodied subjects. The magnitude of changes induced however, was low, generally less than $20 \mathrm{mmHg}$. In a previous report we proposed that if the knee was restricted from extending then stimulation of the quadriceps muscles could also reduce ischial pressures. We have now completed a preliminary study of ischial pressure reduction utilising electrical stimulation applied to the quadriceps muscles in patients with spinal cord injury. The long term objective of the study is the development of an automated system to reduce ischial pressures and hence to aid the prevention of ischial pressure sores.

\section{Materials and methods}

Nine spinal cord injured subjects were recruited for the study. There were 4 quadriplegics and 5 paraplegics. All subjects had complete lesions with an upper motor neuron pattern of neurological loss. Table I lists the 9 subjects included in the study, giving details of mode of injury and level of lesion. Subjects 3 and 4 had a previous history of pressure sores. None of the subjects had a pressure sore present at the 
Table I RTA = road traffic accident

\begin{tabular}{lcccl}
\hline Subject & Age & $\begin{array}{c}\text { Injury } \\
\text { (year) }\end{array}$ & $\begin{array}{c}\text { Model of } \\
\text { injury }\end{array}$ & $\begin{array}{c}\text { Level of } \\
\text { lesion }\end{array}$ \\
\hline 1 & 56 & 1989 & RTA & C 5/6 \\
2 & 47 & 1981 & Farmaccident & C 4/5 \\
3 & 33 & 1982 & RTA & T 4 \\
4 & 28 & 1980 & Spinalsurgery & T 11 \\
5 & 36 & 1984 & RTA & T 6/7 \\
6 & 41 & 1974 & RTA & C 5/6 \\
7 & 34 & 1988 & Gunshot & T 8 \\
8 & 28 & 1983 & RTA & T 12 \\
9 & 21 & 1989 & RTA & T 3 \\
\hline
\end{tabular}

time of inclusion to the study. Prior to entering the study, all subjects underwent a 3-month quadriceps, conditioning programme. A 2-channel neuromuscular stimulator with surface electrodes was used to apply stimulation to the quadriceps 30 minutes/day for at least 5 days/week. The quadriceps were stimulated while the patient was in a sitting position. The active electrode was placed over the motor point of the femoral nerve and the indifferent electrode was placed just proximal to the patella. Once the muscle conditioning programme was completed tests were commenced. Each subject was seated on a foam cushion (density CMRB50) in a model 8L recliner wheelchair. The wheelchair was modified by replacing the normal leg rests with strain-gauged lever arms. The lower limb was attached to the lever arms with broad padded straps just above the ankle joints. To provide a firm pivoting area under the posterior of the thigh a padded steel bar was placed transversely across the front of the cushion. The back rest was tilted posteriorly $5^{0}$ posteriorly and the lever arms angled forward $25^{\circ}$ from the vertical.

Ischial pressures were measured using a pressure monitor based on a recently reported construction model. ${ }^{7}$ The sensor cell used was a sealed bag made of $0.25 \mathrm{~mm}$ thick PVC sheets with a diameter of $28 \mathrm{~mm}$ and is commercially available (Talley Group Limited, Medical Equipment Division Hants, UK). The sensor bags were filled with vegetable oil and sealed to straingauged diaphragm transducers (SenSym SCX15DN, Sensor Technics, Rugby, UK) by a length of PVC tubing with an internal diameter of $2 \mathrm{~mm}$ and a wall thickness of $0.5 \mathrm{~mm}$. The output voltage is linearly related to the applied pressure and the electrical signals were amplified and relayed to an analogue to digital converter (Amplicon PC-26A) installed in an IBM compatible Compaq AT computer. This enabled storage of pressure data for later analysis.

In order to minimise the effect of clothing, each subject wore a pair of thin lycra cycle shorts. The ischia were located by palpation and the sensors were taped to the shorts over the ischia. While sitting the subjects were asked to remain in a relaxed comfortable posture and not to make sudden movements.

Electrical stimulation was applied by means of a programmable stimulator. The stimulation was applied bilaterally and simultaneously via surface electrodes (Axelgard Pals Plus). In order to obtain a smooth tetanic contraction, the parameters of stimulation applied were: pulse width $300 \mu \mathrm{s}$, frequency $20 \mathrm{~Hz}$ and amplitude $100 \mathrm{~mA}$. Stimulation was applied for 10 second intervals with a 20 second rest period. This was repeated after a one minute rest. Pressure readings were sampled at $1 \mathrm{~Hz}$.

Pressure redistribution was assessed in a separate series of tests with subjects 1,2 , and 6. Sensors were placed under the ischia, and between the posterior aspect of the thigh and the pivot bar. These were all areas of anticipated pressure redistribution. Stimulation was applied as above and pressure was sampled at a frequency of $1 \mathrm{~Hz}$. This test was repeated using the Strathclyde cushion in place of the pivot bar with the foam cushion.

\section{Results}

Figure 1 shows the pressure at the right (a) and left (b) ischia during rest and stimulation for all of the subjects. Table II shows the subjects' knee moment with quadriceps stimulation, and their body mass.

A Student's t-test was performed, comparing the mean of the resting pressures with the mean of the stimulated pressures. 


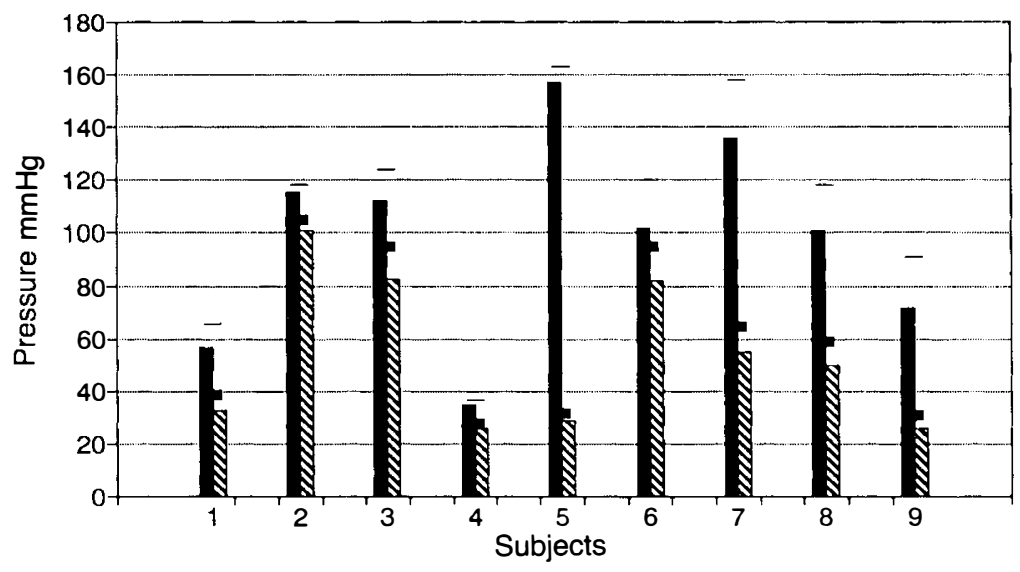

Mean Rest - Rest +SD Mean Stim. - Stim. +SD

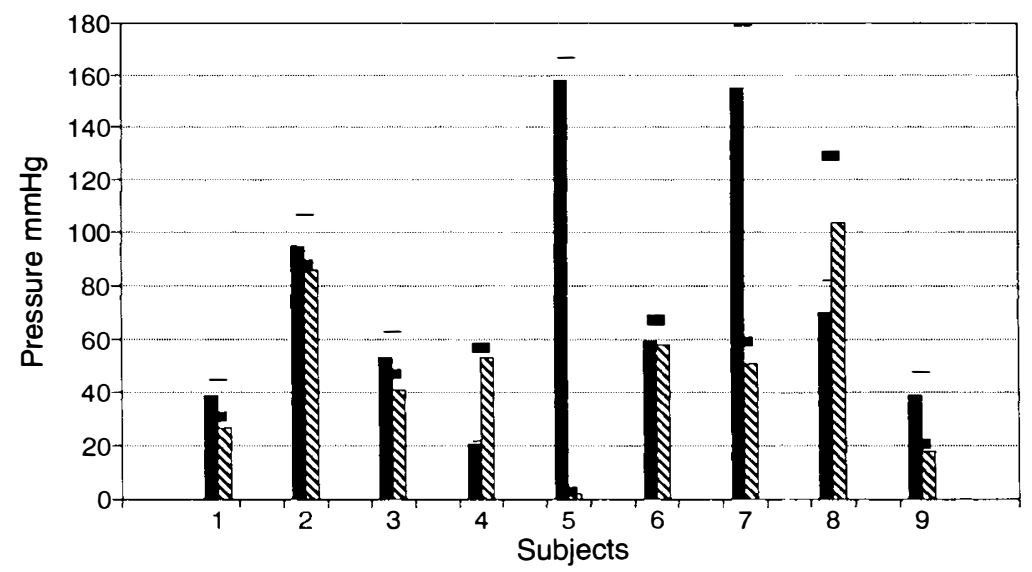

Mean Rest - Rest +SD NW Mean Stim.

Stim. +SD

Figure 1 (a) Pressure at the right ischia during rest and stimulation. (b) Pressure at the left ischia during rest and stimulation.

The difference between resting and stimulated pressures at the ischia were statistically significant $(p<0.001)$ in all except subject 6 . A reduction in pressure occurred at the right ischia of all the subjects and at the left ischia in all except subjects 4 and 8 . The mean resting pressure for the subjects were on the right $99 \mathrm{mmHg}$ and on the left $76 \mathrm{mmHg}$. These dropped during stimulation to mean pressures of on the right $55 \mathrm{mmHg}$ and on the left $49 \mathrm{mmHg}$. The mean pressure drop was on the right side $44 \mathrm{mmHg}$ and on the left side $27 \mathrm{mmHg}$.
The greatest pressure reductions were seen in subjects 5 and 7 . The lowest ischial pressures during stimulation occurred in subject 5 , reducing to $28 \mathrm{mmHg}$ and $2 \mathrm{mmHg}$ at the right and left sides respectively. This represented a drop of approximately $150 \mathrm{mmHg}$ from the resting pressure.

Subjects 4 and 8 had an increase in left ischial pressure on quadriceps stimulation. They had weak quadriceps, the left being less than half the strength of the right. Subjects 1 and 2 were extremely heavy. 
These subjects showed relatively small pressure drops despite a relatively high knee moment for subject 2 . Subject 9 was also heavy, however he had stronger quadriceps than subjects 1 and 2 , and produced a greater pressure relief.

Table III shows the pressures at the thigh with the pivot bar, and with the Strathclyde cushion during rest and stimulation. It also shows the mean pressure reduction at the right and left ischia. The pressures at the thigh when using the pivot bar were higher than with the Strathclyde cushion. The ischial pressure reductions with the Strathclyde cushion were less than those achieved with the pivot bar in half of the cases and greater in the other half.

\section{Discussion}

Our results from this preliminary study indicate that reduction of ischial pressures

Table II

\begin{tabular}{lccc}
\hline Subject & $\begin{array}{c}\text { Right knee } \\
\text { moment } \\
(\mathrm{Nm})\end{array}$ & $\begin{array}{c}\text { Left knee } \\
\text { moment } \\
(\mathrm{Nm})\end{array}$ & Mass $(\mathrm{kg})$ \\
\hline 1 & 13 & 6 & 95 \\
2 & 32 & 47 & 92 \\
3 & 11 & 12 & 51 \\
4 & 5 & 2 & 50 \\
5 & 23 & 25 & 64 \\
6 & 10 & 4 & 60 \\
7 & 20 & 13 & 76 \\
8 & 15 & 7 & 49 \\
9 & 87 & 103 & 85 \\
\hline
\end{tabular}

during sitting is possible using FES. The reductions in this study are greater than those produced by Levine ${ }^{6}$ with stimulation of the gluteal muscles. The quadriceps strength and weight of the subject appear to affect the pressure reduction; however there appears to be no direct relationship between the knee moment/ $\mathrm{kg}$ body mass and pressure drop. The variation between subjects in quadriceps strength may be attributable to varying degrees of spasticity; those with more quadriceps spasticity tended to have greater knee moments. The asymmetrical pressure redistribution shown in subjects 4 and 8 may be due to unilateral weakness of the quadriceps muscles causing tilting of the trunk towards the left side.

The function of the pivot bar was to make a firm pivot point for the thigh. However, the use of the pivot bar may be contraindicated in some subjects due to pressure increases at the front of the thigh during stimulation. In these subjects the Strathclyde cushion may be a viable alternative, as, by design, it has a firm support at the front of the thigh. Further adaptation of the Strathclyde cushion may enable larger ischial pressure reductions without causing too great an increase in pressures at the thighs.

Some of the resting pressures observed in this study were rather high. It should be borne in mind however, that the sensors used were small and placed directly under the ischium. It is therefore to be expected that they would register higher pressures than are generally recorded in clinically practice with the larger inflatable sensors

Table III Pressures $(\mathrm{mmHg})$

\begin{tabular}{|c|c|c|c|c|c|c|c|}
\hline \multirow[b]{2}{*}{ Subject } & \multirow[b]{2}{*}{ Side } & \multicolumn{3}{|c|}{$\begin{array}{l}\text { Foam cushion } \\
\text { with pivot bar }\end{array}$} & \multicolumn{3}{|c|}{$\begin{array}{l}\text { Strathclyde cushion } \\
\text { no pivot bar }\end{array}$} \\
\hline & & $\begin{array}{l}\text { Pressure at } \\
\text { thigh at } \\
\text { rest }\end{array}$ & $\begin{array}{l}\text { Pressure at } \\
\text { thigh with } \\
\text { stim }\end{array}$ & $\begin{array}{l}\text { Ischial } \\
\text { pressure } \\
\text { drop }\end{array}$ & $\begin{array}{l}\text { Pressure at } \\
\text { thigh at } \\
\text { rest }\end{array}$ & $\begin{array}{l}\text { Pressure at } \\
\text { thigh with } \\
\text { stim }\end{array}$ & $\begin{array}{c}\text { Ischial } \\
\text { pressure } \\
\text { drop }\end{array}$ \\
\hline \multirow[t]{2}{*}{1} & $\mathrm{R}$ & 125 & 136 & 24 & 14 & 23 & 13 \\
\hline & $\mathrm{L}$ & 101 & 118 & 12 & 34 & 40 & 14 \\
\hline \multirow[t]{2}{*}{2} & $\mathrm{R}$ & 132 & 226 & 14 & 64 & 99 & 4 \\
\hline & $\mathrm{L}$ & 102 & 153 & 7 & 55 & 61 & 11 \\
\hline \multirow[t]{2}{*}{6} & $\mathrm{R}$ & 113 & 164 & 20 & 75 & 79 & 5 \\
\hline & $\mathrm{L}$ & 55 & 119 & 1 & 40 & 63 & 5 \\
\hline
\end{tabular}


commonly used. Although the pressure changes recorded in these tests were statistically significant, the application in a clinical setting is a more complex issue. The recommended frequency and magnitude of seating pressure reduction necessary to prevent pressure sores is controversial. As yet firm guidelines cannot be given, and it is likely that the tissue tolerance thresholds to pressure are but one of a series of interacting elements in the pathogenesis of pressure sore formation. Many other factors including continence, nutritional status, quality of rehabilitation and motivation of the patient must also play a role.

While the formation of a pressure sore is undoubtedly a multifactorial event, the application of a given pressure for sufficient time to exceed the tissue tolerance is the 'sine qua non' that allows sores to develop. We therefore consider that regular reduction of ischial pressures is a rational approach to prevention, and is likely to remain a cornerstone of preventive therapy for the foreseeable future. The use of quadriceps stimulation to reduce pressures was achieved in these tests with no discomfort to the patient, and with minimal modification to the wheelchair.

There are still some important issues to be dealt with by further study. In the short tests conducted for this study, the onset of muscle fatigue did not prove to be a problem. The development of muscle fatigue system over a more prolonged period needs to be assessed. A standard cushion was used in the first series of tests to ensure reproducibility of results. The pressure response using other commercially available cushions (Jay, Roho, Strathclyde) is presently under investigation as are methods of increasing the effectiveness of the pressure reduction, and the performance of regular pressure reductions over longer time scales. The results will form the basis of a subsequent publication.

Our preliminary experience with this technique suggests that useful ischial pressure relief can be achieved with electrical stimulation applied to the quadriceps muscles, provided the strength of the quadriceps is adequate. If these pressure reductions can be reproduced over longer time scales and on other cushions, the technique may form the basis of an alternative method of pressure sore prevention.

\section{Acknowledgements}

The authors would like to thank the Scottish Home and Health Department for funding this work and the staff and patients of Philipshill Hospital, for their assistance in this study.

\section{References}

1 Jordan MM, Clark MO (1977) Report on the Incidence of Pressure Sores in the Patient Community of the Greater Glasgow Health Board Area on 21st January, 1976. The Bioengineering Unit, University of Strathclyde and the Greater Glasgow Health Board.

2 Guthrie RH, Goulian D (1973) Decubitus ulcers: prevention and treatment. Geriatrics 28: 67-71.

3 Drummond DS, Narechania RG, Rosenthal AN, Breed AL, Lange TA, Drummond DK (1982) A study of pressure distributions measured during balanced and unbalanced sitting. J Bone Joint Surg 64: 1034-1039.

4 Garber S, Krousop T (1982) Body build and its relationship to pressure distribution in the seated wheelchair patient. Arch Phys Med Rehail 63: 17-20.

5 Merbitz CT, King RB, Bleiberg J, Grip JC (1985) Wheelchair push-ups: measuring pressure relief frequency. Arch Phys Med Rehabil 66: 433-438.

6 Levine SP, Kett RL, Cederna BS, Bowers MS, Brooks SV (1989) Electrical muscle stimulation for pressure variation at the seating interface. J Rehail Res Dev 26: 1-7.

7 Barbenel JC, Sockalingham S (1990) Device for measuring soft tissue interface pressures. J Biomed Eng 12: 512-521. 